\title{
Hydraulic and hydrological simulations of the sewer system in the Majorna area, Gothenburg
}

\author{
S. Shahvi ${ }^{1}$, A. Malm ${ }^{1,2} \&$ T. J. R. Pettersson ${ }^{1}$ \\ ${ }^{I}$ Division of Water Environment Technology, \\ Department of Civil and Environmental Engineering, \\ Chalmers University of Technology, Sweden \\ ${ }^{2}$ Gothenburg Water, Sweden
}

\begin{abstract}
As long as cities and urban life have been developed during the centuries, the conveying of wastewater and sewage have been important issues for municipalities and other authorities. The goal of municipalities is to convey, treat and reuse the wastewater in a way that does not harm public health and the environment.

In the year 2010, Gothenburg Water utility decided to study and improve the sewer network system of the Majorna region, with a total area of 130 hectares, located in Gothenburg city. Hydraulic and hydrological properties of the sewer system were measured, modelled and simulated. Most of the input data needed for simulation was provided by the Gothenburg Water utility databases and a GIS-based map of Gothenburg sewer systems. The site measurements were taken between October and December 2010 and at two manholes where the measuring devices have been installed.

The calibration of the model has shown that although there is a good correlation between the model results and the measured values at one of the measuring nodes at the area, there is a difference in the other one; the reason for which should be studied and investigated in another study.

Finally, the tests and comparisons between the sewer system in this area and the standard values have shown that pipe leakages are the most problematic matter of the system and solving this problem will improve the system considerably.
\end{abstract}

Keywords: sewer system, GIS, hydraulic and hydrological simulation, leakage. 


\section{Introduction}

Wastewater is defined as liquid or solid wastes removed from residences, institutions, and commercial and industrial establishments, together with groundwater, surface water and stormwater (Metcalf and Eddy [1]).

As long as cities and urban life have been developed; the conveying of sewage has become an important issue for municipalities. The problems caused by wastewater flows in terms of public health, aquatic species or aquatic habitat, alongside occasional fish kills, numerous beach closures and potential odours and solids deposits in the receiving water body (EPA [2]) were all reasons for a considerable amount of attention to be given to this subject.

The goal of municipalities is to convey, treat and reuse the wastewater in a way that does not harm public health and the environment. They always try and test new methods to improve the sewage network system and wastewater treatment plants.

The goal of this work is to suggest methods to test and improve the sewer network in the Majorna area located in Gothenburg city so that less stormwater flow be conveyed to the wastewater treatment plant Ryaverket and released instead into the receiving water, the river Göta Älv.

\section{An overview to urban sewage}

In order to gain a proper understanding of urban sewage, a brief introduction about sewer systems and pipe leakages - one of the most important matters for urban sewer systems - is addressed in this chapter.

\subsection{Sewer systems}

Generally, there are two kinds of sewer systems in each wastewater network. The one which conveys both sanitary sewage and stormwater through a single pipe (EPA [2]) is called a combined system and the other, which conveys the sanitary and stormwater flow through two separate pipes, is referred to as a separate system. Choosing each of these two systems has been a controversial discussion for decades and most research has not given one straight answer (Welker [3]; Brombach et al. [4]). Research which has been done on this subject during past years mostly has had a focus on the effects of these systems on the environment.

\subsection{Pipe leakages in sewer networks}

Leakages in urban sewer systems are usually caused by a number of factors, including aging, excessive demand, misuse, exposure, mismanagement and neglect of the system (Wirahadikusumah et al. [5]) that later lead to deteriorated pipes, manholes, and pump stations (EPA [6]).

In the case of leakages in sewer systems due to groundwater level, two phenomena occur; infiltration and exfiltration. 
Infiltration occurs when the sewer system is located beneath the groundwater table and water enters the sewer systems through cracks and joints of pipes. This causes extra and unwanted flow entering the sewer system and wastewater treatment plants.

Exfiltration, on the other hand, occurs when the sewer system is located above the groundwater table and sewage leaks through the pipes and contaminates the groundwater. Contamination may include high levels of suspended solids, pathogenic microorganisms, toxic pollutants, floatables, nutrients, oxygen-demanding organic compounds, oil and grease (EPA [6]).

\section{Material and method}

In this section first some brief descriptive information about Gothenburg city and the Majorna area is presented and then the methodologies used in the simulation of a sewer network are described.

\subsection{Gothenburg city and the Majorna area}

The city of Gothenburg is located in the south west part of Sweden and is the second largest city of the country. Almost all of the 500,000 inhabitants are connected to the wastewater system.

The wastewater network system totals about $2436 \mathrm{~km} .871 \mathrm{~km}$ of this network are stormwater pipelines, $980 \mathrm{~km}$ are sanitary water pipelines, $401 \mathrm{~km}$ are combined pipe lines and also there are $182 \mathrm{~km}$ of sanitary water pressure line and about $1 \mathrm{~km}$ of stormwater pressure pipes. The wastewater network also includes a 124-km length tunnel to the wastewater treatment plant, Ryaverket. The whole amount of wastewater which enters the wastewater treatment plant, Ryaverket, from the city of Gothenburg is $98.4 \mathrm{Mm}^{3}$ which from this amount $40 \mathrm{Mm}^{3}$ is sanitary water.

The Majorna region is located in the south west part of Gothenburg city. The total area of Majorna is about 130 hectares and it has the person equivalence of about 17,000 . The sanitary flow produced in this area is about $39.6 \mathrm{l} / \mathrm{s}$. In the area there are both combined and separate sewer systems, some outlets to the river and a tunnel to Ryaverket. The sewer network of the area is shown in Figure 1 (Göteborg Vatten [7]).

A GIS-based map of the wastewater network in the city of Gothenburg contains important information such as the pipes and their properties, the CSOs, the borders of the areas, the households' connections to the main system, the kind of sewer system, the manholes, the counter lines, etc.

\subsection{Measuring}

The measurements in this region were taken in sanitary pipes and in the period between October $28^{\text {th }}$ and December $21^{\text {st }}$ of 2010 . The measuring nodes were two manholes named ASN14276 and ASN14294 where the sewage discharge 


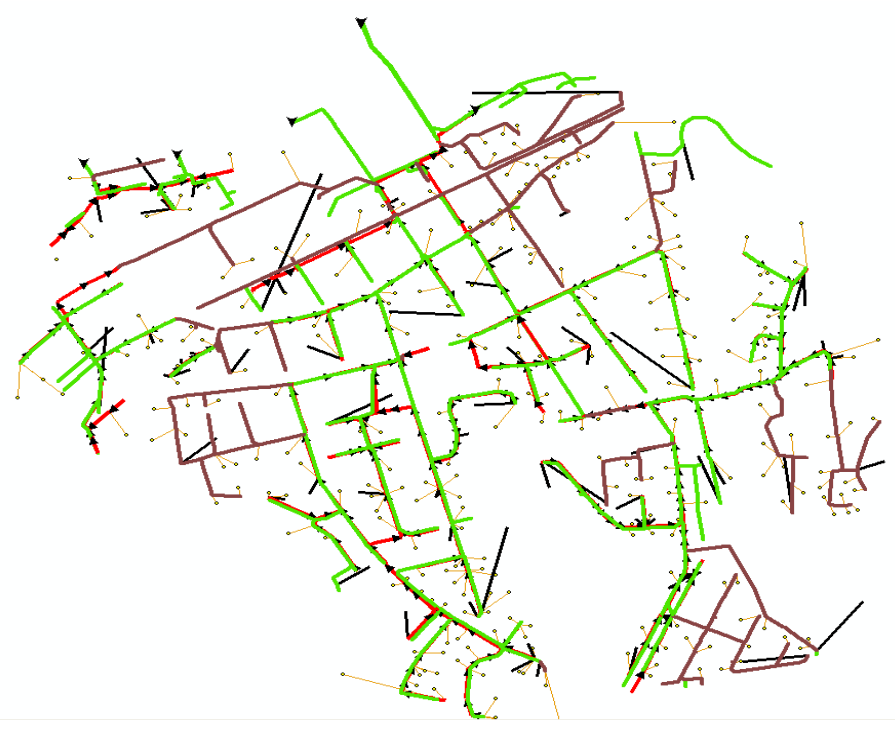

Figure 1: $\quad$ Sewer network system in the Majorna area. Brown lines: combined sewer system; green lines: stormwater pipes; red lines: sanitary pipes. (See online for colour version.)

and volume values were measured and analysed. This data was later used for calibration and for comparing the network with standard values to test the real situation of the network.

\subsection{Hydraulic modelling}

Hydrodynamics is one the most important aspects of each sewage network, as it defines the flow's movement in different parts of the system and also shows the requirement of the system to different hydraulic elements (DHI [8]). The network input data in this project work; such as pipes, CSOs, weirs, outlets, nodes and manholes has been mostly imported from the Gothenburg GIS-based map. It should be noted that there is no pumping station in this network as the flow moves in the direction of gravity. In this project MOUSE, one of the tools in MIKE URBAN software made by the DHI (Danish Hydraulic Institute), is used for hydraulic modelling.

\subsection{Hydrological modelling}

MOUSE software has the ability of modelling the rainfall-runoff models in urban areas. This process is done within some steps:

1. Creating the main catchment and splitting it to some sub-catchments.

2. Calculation of sub-catchments properties.

3. Connection of sub-catchments to the sewer network.

4. Importing the rainfall input data.

5. Runoff simulation (DHI [8]). 
In this project the whole region of Majorna was regarded as the main catchment and it was then divided into 24 sub-catchments. The division was made based on different criteria, such as: the topology of the land, the different types of sewage pipes (separated or combined) and also according to their drainage node. Generally it is done so that the stormwater of a certain region being released to one sub-catchment and that each sub-catchment contains the same sewer type and also a drainage node (the connection to sewer network) does not receive a high load of flow. This is shown in Figure 2. Figure 3 presents a schematic view of sub-catchments and the network.

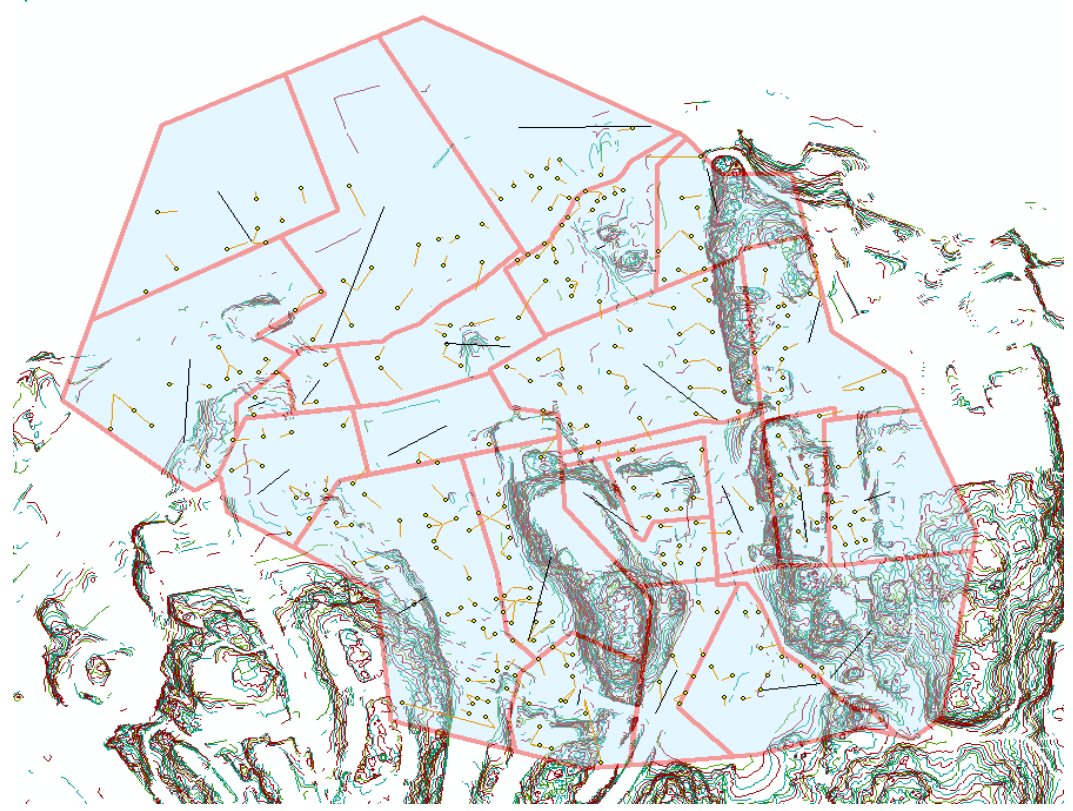

Figure 2: The main catchment and sub-catchments in the Majorna area.

After definition of the sub-catchments their imperviousness coefficients were calculated according to eqn. (1).

$$
\varphi=\frac{\left(A_{1} \varphi_{1}+A_{2} \varphi_{2}+\cdots+A_{\tau} \varphi_{\tau}+A_{v} \varphi_{v}\right)}{\left(A_{1}+A_{2}+\cdots+A_{\tau}+A_{v}\right)}
$$

where $A_{1}, A_{2} \ldots$ are areas of region of sub-catchments which have the same surface cover (such as roof, asphalt and ...) and $\phi_{1}, \phi_{2} \ldots$ are their imperviousness coefficients (Svenskt Vatten [9]).

The one-year rainfall data which is used for this project work is the Gothenburg annual rainfall measurements provided by Gothenburg Water utility (Göteborg Vatten [10]). 


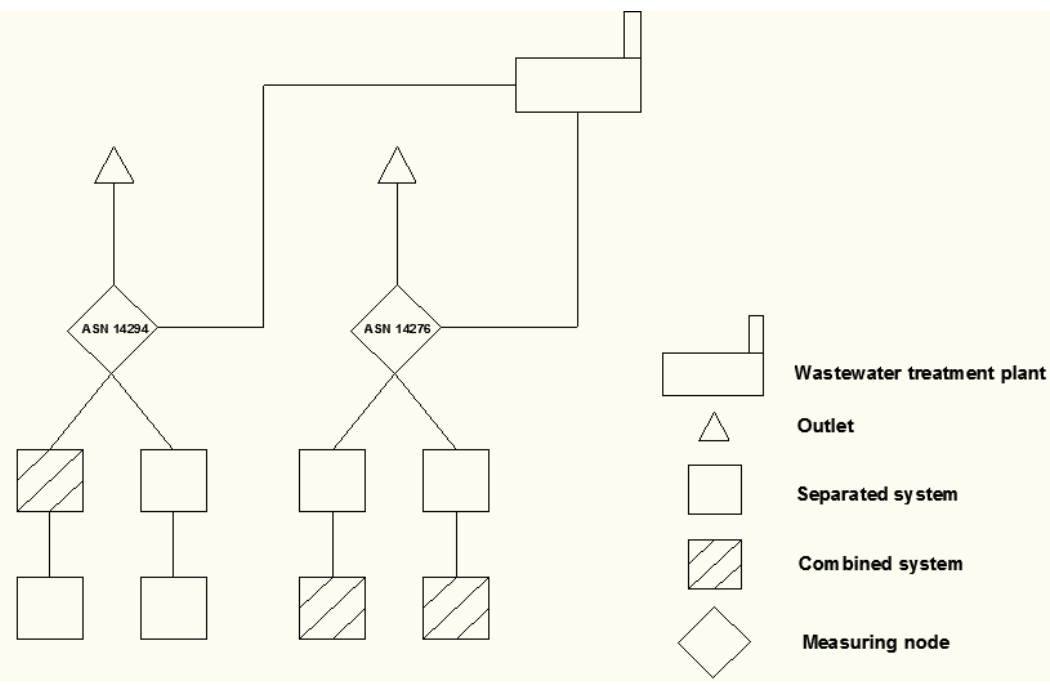

Figure 3: Schematic illustration of sub-catchments in the network.

\subsection{Calibration and validation}

The period of October $28^{\text {th }}$ until December $9^{\text {th }}$ was used for calibration and the period December $10^{\text {th }}$ to December $21^{\text {st }}$ was used for validation.

In order to make the calibration, first, the rainfall effects were studied. It was observed that the rainfall effects are higher at simulation than in reality, hence it was decided to reduce the imperviousness coefficient of catchments since, in reality, some of the wastewater produced at each catchment does not enter the sanitary pipes and instead infiltrates into the soil or enters the stormwater pipes.

To match the amount of sanitary water, the amount of rainfall water enters the gullies around buildings was added as sanitary flow in the model as, due to oldness of pipes at some locations of this area, the stormwater of these drainage facilities are entering the sanitary pipes. In addition, as there is natural leakage at each sewer network it was decided to add some constant flows upstream of the measurement nodes.

\section{Results}

After modelling the hydraulic and hydrological properties of the Majorna sewer system, the simulation results were compared with site measurements and calibration was made. The statistical analyses for results for the two measuring nodes are presented in this chapter.

Statistical analysis for node ASN14276 has shown that the maximum positive difference between modelled and measured values is $0.055 \mathrm{~m}^{3} / \mathrm{s}$ and the maximum negative difference is equal to $-0.064 \mathrm{~m}^{3} / \mathrm{s}$. The total measured volume is $54406 \mathrm{~m}^{3}$ and the total modelled volume is $46139 \mathrm{~m}^{3}$ which means a 


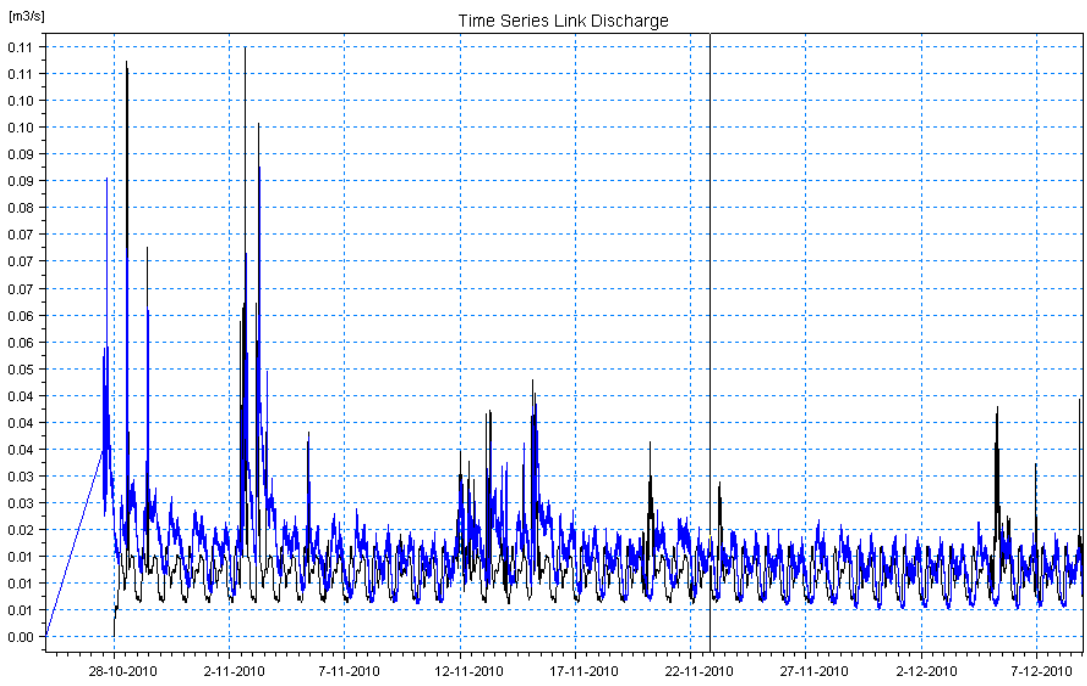

Figure 4: $\quad$ Computed and measured values at node ASN14276.

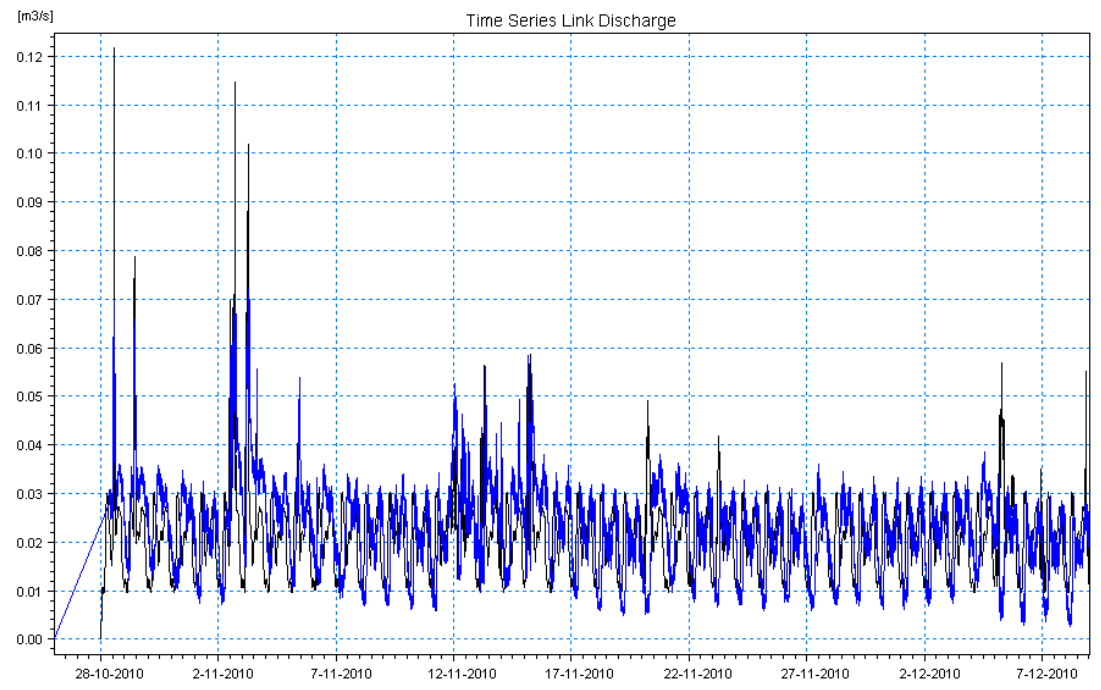

Figure 5: Computed and measured values at the node ASN14294.

volume error of $-15.2 \%$ (the minus mark shows a deficiency in modelled value). In addition, the peak measured value is $0.087 \mathrm{~m}^{3} / \mathrm{s}$ and the peak modelled value is equal to $0.106 \mathrm{~m}^{3} / \mathrm{s}$ which means the peak error is equal to $21.2 \%$. The errors calculated for this node are a little high.

Statistical analysis for node ASN14294 has shown that the maximum positive difference between modelled and measured values is $0.057 \mathrm{~m}^{3} / \mathrm{s}$ and the maximum negative difference is equal to $-0.039 \mathrm{~m}^{3} / \mathrm{s}$. The total measured 
volume is $81173 \mathrm{~m}^{3}$ and the total modelled volume is $76570 \mathrm{~m}^{3}$ which means a volume error of $-5.7 \%$ (the minus mark shows a deficiency in modelled value). Also, the peak measured value is $0.072 \mathrm{~m}^{3} / \mathrm{s}$ and the peak modelled value is $0.122 \mathrm{~m}^{3} / \mathrm{s}$ which means the peak error is equal to $68.4 \%$. Although the error calculated for total volume shows a good correlation between measured and modelled values the error between peaks is high.

\section{Discussion}

Some important key factors which represent the operation efficiency of the network system have been calculated. These parameters have been taken from annual average values of Gothenburg city to Ryaverket wastewater treatment plant.

The first key number used is the leakage and drainage value which shows the amount of leakage in the system and has the standard value of $0.8-1 \mathrm{l} / \mathrm{s} . \mathrm{km}$ (Naturvårdsverket [11]). It was calculated based on eqn. (2).

$$
L D M=\frac{q_{l d r}}{\text { sanitary pipes length }+ \text { combined pipes length }}
$$

where $\mathrm{q}_{1 \mathrm{dr}}$ is the summation of total leakage and drainage flow. This parameter has been calculated for sub-catchments upstream of the two measuring nodes and for the whole period of simulation, October $28^{\text {th }}$ to December $21^{\text {st }}$.

The results for this value are presented in the tables below.

Table 1: $\quad$ Leakage and drainage factor for the node ASN14276.

\begin{tabular}{|c|c|c|c|}
\hline $\begin{array}{c}\text { Drainage discharge } \\
\text { volume }(1 / \mathrm{s})\end{array}$ & $\begin{array}{c}\text { Leakage discharge } \\
\text { volume }(1 / \mathrm{s})\end{array}$ & $\begin{array}{c}\text { Pipe } \\
\text { length }(\mathrm{km})\end{array}$ & $\begin{array}{c}\text { LDM } \\
(1 / \mathrm{s} . \mathrm{km})\end{array}$ \\
\hline 2 & 4 & 4.1 & 1.5 \\
\hline
\end{tabular}

Table 2: $\quad$ Leakage and drainage factor for the node ASN14294.

\begin{tabular}{|c|c|c|c|}
\hline $\begin{array}{c}\text { Drainage discharge } \\
\text { volume }(1 / \mathrm{s})\end{array}$ & $\begin{array}{c}\text { Leakage discharge } \\
\text { volume }(1 / \mathrm{s})\end{array}$ & $\begin{array}{c}\text { Pipe } \\
\text { length }(\mathrm{km})\end{array}$ & $\begin{array}{c}\text { LDM } \\
(1 / \mathrm{s} . \mathrm{km})\end{array}$ \\
\hline 0.93 & 10 & 6 & 1.8 \\
\hline
\end{tabular}

As can be seen, both calculated leakage values are more than the standard value which is $0.8 \mathrm{l} / \mathrm{s} . \mathrm{km}$ (Naturvårdsverket [11]). This means that the pipelines in the whole sewer system at Majorna are old or not fixed properly and hence are leaking a lot.

The second key factor used is the degree of delineation, which represents the amount of stormwater in the system and its standard value is equal to 1.8. This parameter has been calculated on the basis of eqn. (3).

$$
U S G=\frac{q_{t o t}}{q_{s}}
$$


where $\mathrm{q}_{\text {tot }}$ is the total flow of wastewater and $\mathrm{q}_{\mathrm{s}}$ is the sanitary flow. The results for this value are presented in the tables below.

Table 3: $\quad$ Delineation factors for the node ASN14276.

\begin{tabular}{|c|c|c|}
\hline Total flow $\left(\mathrm{m}^{3}\right)$ & Sanitary flow $\left(\mathrm{m}^{3}\right)$ & USG \\
\hline 58850 & 50960 & 1.8 \\
\hline
\end{tabular}

Table 4: $\quad$ Delineation factors for the node ASN14294.

\begin{tabular}{|c|c|c|}
\hline Total flow $\left(\mathrm{m}^{3}\right)$ & Sanitary flow $\left(\mathrm{m}^{3}\right)$ & USG \\
\hline 98480 & 47490 & 2.1 \\
\hline
\end{tabular}

As it is seen, the USG values for the two nodes, especially for ASN14294, are also higher than the standard value which means the stormwater transported to the wastewater treatment plant from this region is more than standard. It should be noted, however, that there are combined sewer areas upstream which will result in more stormwater in the system.

A suggestion for improvement of the sewer system in this case study is to reduce the base flow or the constant flows by $30 \%$ and find out the sensitivity of the system to this criterion. The results are presented in the tables below.

Table 5: Factors after reducing the base flow by $30 \%$ at the node ASN14276.

\begin{tabular}{|c|c|c|c|}
\hline Factor & Old value & New value & Percentage of reduction \\
\hline LDM & 1.5 & 0.77 & 49 \\
\hline USG & 1.82 & 1.39 & 24 \\
\hline
\end{tabular}

Table 6: Factors after reducing the base flow by $30 \%$ at the node ASN14294.

\begin{tabular}{|c|c|c|c|}
\hline Factor & Old value & New value & Percentage of reduction \\
\hline LDM & 1.8 & 0.65 & 64 \\
\hline USG & 2.07 & 1.28 & 38 \\
\hline
\end{tabular}


Hence, this method seems effective as the values of both leakage and delineation key factors have reduced and are appropriate according to the standard values of each.

\section{Conclusion}

Simulation of the sewer system network in the Majorna region has shown that there is the problem of leakage in the system when it was compared with the standard values.

It has shown that a reduction of $30 \%$ in the constant flows, which describes the leakages in the system, will lead to a leakage reduction of $49 \%$ for the subcatchments upstream ASN14276 and 64\% for the sub-catchments ASN14294.

Reduction of base flow by $30 \%$ also affected the USG factor which is a representative of the amount of stormwater in the system. According to this improvement method, the amount of stormwater to the wastewater treatment plant for sub-catchments upstream the node ASN14276 has reduced by $24 \%$ and for the ones upstream the node ASN14294 reduced by 38\%.

As a general recommendation, according to simulations, the Majorna sewer system has a lot of leakages. Repair of pipes junction and other properties will lead to a better system function, a lower risk of groundwater pollution and also less stormwater flow to the wastewater treatment plant, Ryaverket.

\section{Acknowledgements}

This project was funded by Göteborg Vatten (Gothenburg Water Utility). The authors would like to thank Malin Suneson and Håkan Strandner for their help and advice in the technical part of the project.

\section{References}

[1] Metcalf., Eddy., Wastewater Engineering, Treatment and Reuse, McGrawHill: New York, 2004.

[2] United States Environmental Protection Agency; Combined Sewer Overflow Management Fact Sheet, EPA: Washington, D.C., 1999.

[3] Welker, A., Emissions of pollutant loads from combined sewer systems and separate sewer systems-which sewer system is better?. Proc. of the $11^{\text {th }}$ International Conference on Urban Drainage: Edinburg, 2008.

[4] Brombach, H., Weiss, G. \& Fuchs, S., A new database on urban runoff pollution: comparison of separate and combined sewer systems. Water Science and Technology, 51(2), pp. 119-128, 2005.

[5] Wirahadikusumah, R., Abraham, D.M., Iseley, T. \& Prasanth, R.K., Assessment technologies for sewer system rehabilitation. Automation in Construction, 7, ELSEVIER: Amsterdam, pp. 259-270, 1998.

[6] United States Environmental Protection Agency; Exfiltration in Sewer Systems, EPA: Cincinnati, Ohio, 2000. 
[7] Göteborg Vatten, www.goteborg.se/vatten

[8] DHI, MOUSE User Manual and Tutorial, DHI: Hørsholm, 2009.

[9] Svenskt Vatten, Dimensionering av allmänna avloppsledningar (Design of public sewer systems. In Swedish), Svenskt Vatten AB: Stockholm, 2004.

[10] Göteborg Vatten, Goteborg Vatten databases, 2011.

[11] Naturvårdsverket (Environmental Protection Agency), Nyckeltal för läckoch dränvatten i avloppsnät (key data for leakage and drainage water in sewer systems. In Swedish), Naturvårdsverket: Stockholm, 1996. 